\title{
AVALIAÇÃo TÉRMICA DE PLACAS DE ARGAMASSA DE CIMENTO E CASCA DE ARROZ AQUECIDAS POR RESISTÊNCIA ELÉTRICA
}

\author{
LUIZ A. ROSSI ${ }^{1}$, PAULO E. DOS R. CARDOSO ${ }^{2}$, ANTONIO L. BERALDO ${ }^{3}$
}

RESUMO: Neste trabalho, apresenta-se uma proposta alternativa para o sistema de aquecimento de piso por resistência elétrica em granjas de aves e suínos. Após o dimensionamento do sistema, foram confeccionadas placas com argamassa de cimento, areia e casca de arroz, com diferentes traços, a fim de avaliar esse material alternativo de construção, sendo construído um controlador eletrônico de temperatura para dar mais autonomia ao sistema de aquecimento. O sistema mostrou-se eficiente no controle da temperatura da placa. Dentre os traços analisados, aquele com a placa mista de argamassa convencional e casca de arroz demonstrou melhor desempenho.

PALAVRAS-CHAVE: conforto térmico, aquecimento de piso, casca de arroz.

\section{THERMAL EVALUATION OF RICE HUSK AND CEMENT MORTAR BOARDS WARMED BY ELECTRIC RESISTANCE}

\begin{abstract}
An alternative proposal for floor heating system by means of electric resistance for both chick and piggy installation is presented in this work. Several formulations of rice husk and cement mortar boards were used. An electronic device controlled all board temperature. This system presented a good efficiency design. The conventional cement mortar mixed with rice husk showed a better performance.
\end{abstract}

KEYWORDS: thermal comfort, floor heating, rice husk.

\section{INTRODUÇÃO}

Os sistemas auxiliares de conforto térmico para animais podem ser encontrados em diversas formas, tais como campânulas a gás, campânulas elétricas, lâmpadas infravermelhas, fornalhas e placas aquecidas por meio de resistências elétricas.

ABREU (1994) demonstrou que o sistema de placas aquecidas apresenta melhores resultados quando comparado aos outros, principalmente pelo fato de que esse sistema supre o calor de baixo para cima, ao contrário dos demais. Também é relevante que, no sistema de placas aquecidas, não há emissão de gases tóxicos, consumo de oxigênio, risco de explosões ou a criação de condições ambientais que modifiquem o comportamento dos animais. Outros estudos levantaram quais seriam as condições térmicas ideais para a criação de pintinhos e leitões. Os pintinhos devem ser mantidos sob temperatura em torno de $35^{\circ} \mathrm{C}$ na $1^{\mathrm{a}}$ semana; $32{ }^{\circ} \mathrm{C}$ na $2^{\mathrm{a}} ; 29^{\circ} \mathrm{C}$ na $3^{\mathrm{a}} ; 26^{\circ} \mathrm{C}$ na $4^{\mathrm{a}}$, e $23{ }^{\circ} \mathrm{C}$ na $5^{\mathrm{a}}$ semana, quando, então, o mecanismo de termorregulação dos pintinhos já se encontra plenamente desenvolvido (CURTIS, 1983; DEATON \& REECE, 1970; MILLIGAN \& WINN, 1964). Da mesma forma, os leitões devem ser mantidos a $26{ }^{\circ} \mathrm{C}$ nos primeiros dias de idade, descendo gradativamente para 15,5 a $18,3^{\circ} \mathrm{C}$ na continuidade do crescimento (ÁVILA et al., 1995).

\footnotetext{
${ }^{1}$ Eng ${ }^{\underline{o}}$ Eletricista, Prof. Dr., Departamento de Construções Rurais, Faculdade de Engenharia Agrícola, UNICAMP, Caixa Postal 6011, Campinas - SP, Fone: (0XX19) 3788.1041, rossi@agr.unicamp.br

${ }^{2}$ Eng $^{\mathrm{o}}$ Eletricista, pós-graduando, FEEC/UNICAMP, Campinas - SP.

${ }^{3}$ Eng $^{\mathbf{0}}$ Agrícola, Prof. Dr., Departamento de Construções Rurais, FEAGRI/UNICAMP, Campinas - SP, beraldo@ agr.unicamp.br

Recebido pelo Conselho Editorial em: 30-4-2002

Aprovado pelo Conselho Editorial em: 18-2-2004
} 
A agroindústria gera grande quantidade de resíduos e, dentre eles, situa-se a casca de arroz. Trabalhos desenvolvidos propondo o uso dessa matéria-prima evidenciaram a sua adequação para fins de obtenção de materiais de construção (ZUCCO, 1999; BERALDO \& TOJAL, 2001). Na confecção de compósitos biomassa vegetal - cimento Portland, a casca de arroz, a exemplo de outras biomassas vegetais, responde pela leveza e pelas características de isolamento termoacústico do compósito; ao cimento Portland cabe a tarefa de envelopar a biomassa vegetal (BERALDO, 1997).

A massa específica aparente do material é da ordem de $1.850 \mathrm{~kg} \mathrm{~m}^{-3}$ (dependendo do traço adotado); sua resistência à compressão simples situa-se em torno de 9,0 MPa (TOJAL, 2002).

Atualmente, nos locais onde se utilizam sistemas auxiliares de aquecimento, o controle da temperatura é feito de forma manual. No mercado, estão disponíveis vários componentes eletrônicos e dispositivos elétricos para a medição de temperaturas, os quais permitem a construção de equipamentos para o seu controle.

Este trabalho teve os objetivos de confeccionar placas de argamassa de cimento, areia e casca de arroz aquecidas por meio de resistência elétrica, avaliar o desempenho térmico dessas e construir um controlador eletrônico de tal forma que, juntos, dessem origem ao sistema de aquecimento.

\section{MATERIAL E MÉTODOS}

\section{Descrição do sistema de aquecimento}

O sistema de placas aquecidas eletricamente consiste em uma placa confeccionada com argamassa de cimento Portland, areia e casca de arroz. Na mistura, distribuiu-se, o mais uniformemente possível, um fio de resistência elétrica de níquel-cromo, isolado eletricamente da placa. Para o dimensionamento da resistência elétrica, foi utilizada a metodologia descrita por INCROPERA \& DeWITT (1985), citados em ABREU (1994). Ela é baseada na Lei de Conservação de Energia:

$$
\mathrm{We}+\mathrm{Wg}=\mathrm{Ws}+\mathrm{Wa}
$$

em que,

We - taxa de calor que entra no sistema, J;

$\mathrm{Wg}$ - taxa de calor gerada pelo sistema, $\mathrm{J}$;

Ws - taxa de calor que sai do sistema, J, e

Wa - taxa de calor armazenada pelo sistema, J.

\section{Resistência elétrica}

A resistência elétrica utilizada tem as seguintes características:

- Fio térmico: aço/cromo/níquel, têmpera dura;

- Isolação: composto termoplástico de cloreto de polivinila, antichama, AWG 18;

- Temperatura na capa na tensão indicada: $65^{\circ} \mathrm{C}$;

- Comprimento para o módulo: 5,5 m;

- Tensão para o módulo: 15,9 V;

- Resistência do módulo: $2 \Omega$;

- Carga para o módulo em 15,9 V: 126 W;

- Carga total: $1008 \mathrm{~W}, \mathrm{e}$

- Manta de poliuretano: dá suporte físico e direciona o calor.

O sistema foi projetado para controlar oito módulos de resistência conectados em série. Na Figura 1, mostra-se um desses módulos de resistência. 


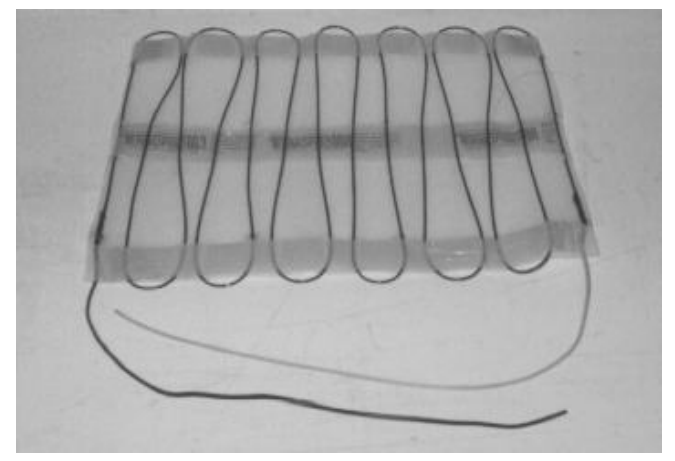

FIGURA 1. Fio de resistência utilizado.

\section{Confecção das placas}

Misturou-se o cimento com a areia e, a seguir, adicionou-se a casca de arroz. Colocou-se a água de amassamento e efetuou-se a homogeneização da mistura. Os traços (em massa) escolhidos e utilizados na composição e confecção das placas foram:

Argamassa de cimento e areia: 1:3:0,5 (cimento:areia:água), e

Argamassa de cimento e areia, com casca de arroz: 1:2,0:0,25:0,5 (cimento:areia:casca:água).

Combinando os traços acima, foram confeccionados três modelos de placas, nos quais se utilizaram moldes metálicos com dimensões internas de $40 \mathrm{~cm}$ x $50 \mathrm{~cm}$ x $2,5 \mathrm{~cm}$, cujas características foram:

Modelo 1: argamassa de cimento e areia;

Modelo 2: a metade superior feita de argamassa de cimento e areia, e a metade inferior feita de argamassa de cimento, areia e casca de arroz, e

Modelo 3: placa feita totalmente de argamassa de cimento, areia e casca de arroz.

\section{Sistema de confecção}

A confecção das placas seguiu o seguinte procedimento:

Modelo 1: primeiramente, foi preenchida metade do molde metálico com a massa de cimento; em seguida, foi colocado o fio de resistência elétrica, sem a manta de poliuretano, devidamente disposto para fornecer um aquecimento uniforme à placa e, finalmente, o molde foi preenchido totalmente com argamassa de cimento;

Modelo 2: primeiramente, foi preenchida metade do molde metálico com argamassa de cimento; em seguida, foi colocado o fio de resistência elétrica, sem a manta de poliuretano e, finalmente, o molde foi preenchido totalmente com argamassa de cimento, areia e casca de arroz, e

Modelo 3: procedimento idêntico ao do Modelo 1, porém utilizando-se de argamassa de cimento, areia e casca de arroz.

Em todos os modelos, o molde metálico foi disposto sobre uma mesa vibratória a fim de fazer com que a argamassa de cimento e areia, ou aquela com a inclusão da casca de arroz, se distribuísse de modo uniforme. Algumas placas receberam em seu interior, juntamente com a resistência elétrica, $o$ sensor de temperaturas, cuja função era fornecer a temperatura interna ao controlador, executando a realimentação necessária para manter a placa na temperatura escolhida.

Para se decidir qual dos modelos de placa que melhor atendia às condições do sistema de aquecimento, foi necessária a realização de alguns testes. Para isso, a placa ideal deveria concentrar 
mais calor na superfície superior do que na inferior e apresentar o menor tempo de estabilização. Para a tomada dessa decisão, foi realizado o teste de resposta ao degrau, o qual consiste na aplicação de um nível de tensão adequado às exigências do dispositivo, que, neste caso, correspondia ao nível máximo de tensão da resistência utilizada.

\section{Controle eletrônico da temperatura}

O circuito de controle foi montado em um proto-board, no qual foi possível testar todos os blocos do controlador. Após os testes, o protótipo do controlador foi montado em uma placa universal e acondicionado em caixa própria, com dissipador de calor e cooler para manter a temperatura interna baixa. Efetuou-se o acabamento e colocou-se legenda nos comandos, tanto no painel frontal como no traseiro. Na Figura 2, apresenta-se o protótipo do controlador.
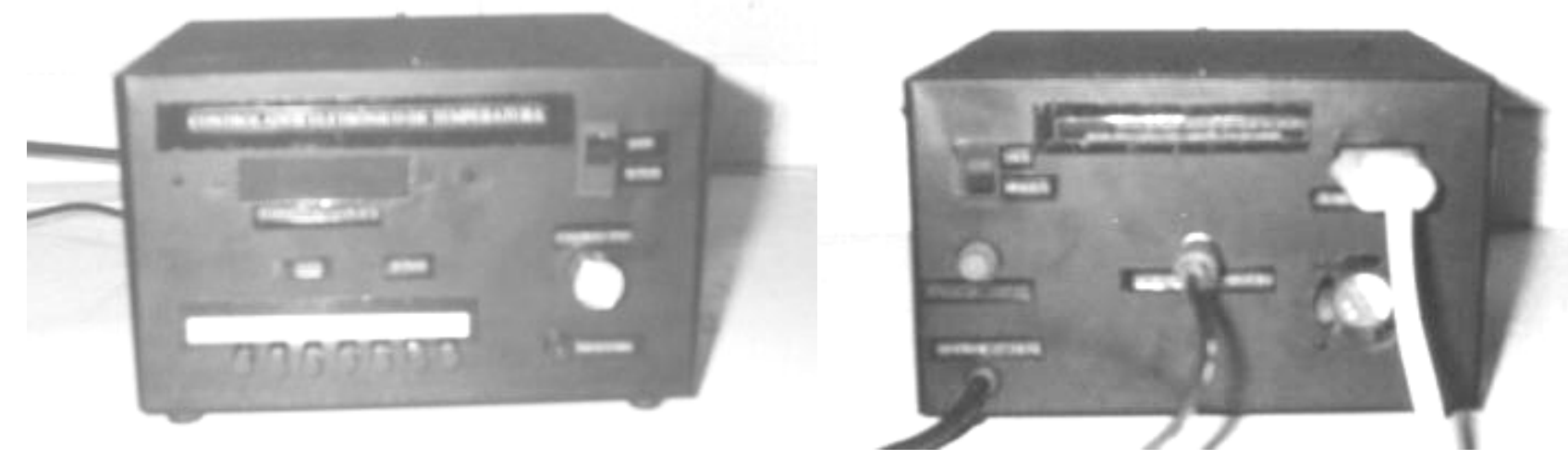

FIGURA 2. Controlador eletrônico de temperatura: painéis frontal e traseiro.

\section{Sensor de temperatura}

O componente eletrônico utilizado na medida de temperatura foi o LM35D (Figura 3). Esse componente faz uma conversão linear de temperatura em tensão, na relação $10 \mathrm{mV} /{ }^{\circ} \mathrm{C}$ e pode medir temperaturas na faixa de $-55{ }^{\circ} \mathrm{C}$ a $+150{ }^{\circ} \mathrm{C}$, sendo disposto no interior da placa, a fim de obter a medida exata da temperatura na placa.

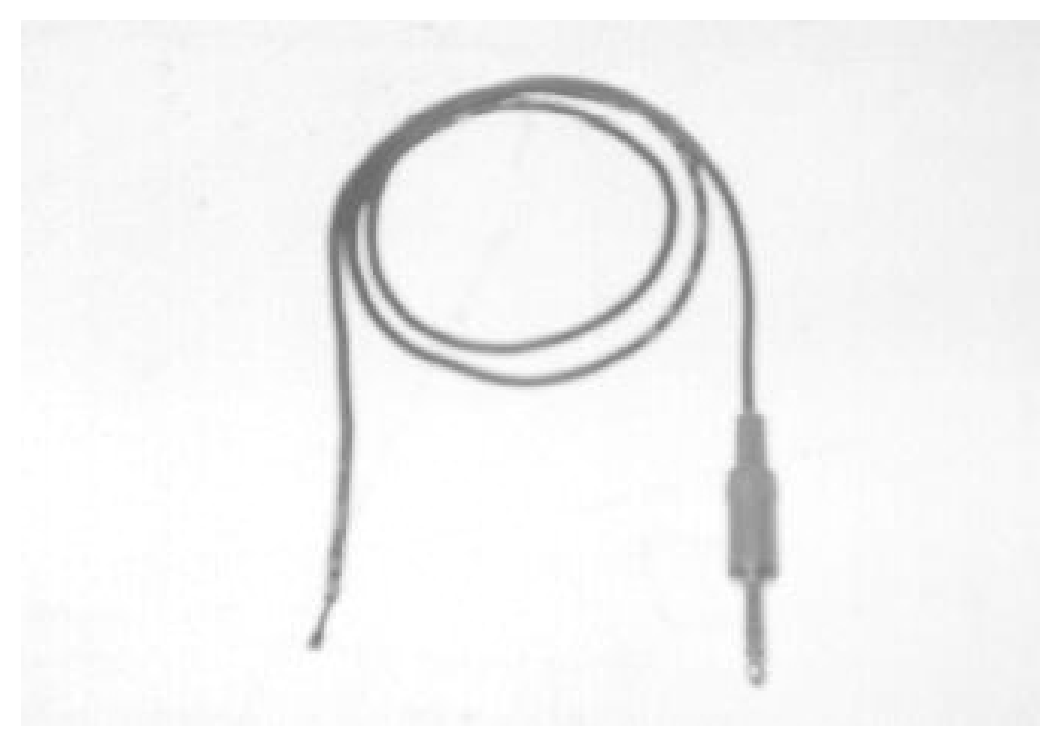

FIGURA 3. Sensor de temperatura LM35D com cabo e conector. 


\section{Base de temperaturas}

Como era preciso fazer uma comparação entre as temperaturas medida e desejada na placa, tornou-se necessário um circuito que indicasse com qual temperatura a placa deveria estar para cada idade dos animais. Como o LM35D fornece tensão como grandeza elétrica, foi construído um circuito em que tais temperaturas pudessem ser vistas como tensões. Dessa forma, um divisor de tensão adaptado, que atendia às exigências tanto de aves como de suínos, pôde ser utilizado, fornecendo as temperaturas indicadas na Tabela 1. Essas temperaturas são os valores máximos que podem ser regulados no controlador eletrônico.

TABELA 1. Temperaturas máximas reguladas no controlador eletrônico.

\begin{tabular}{ccc}
\hline Idade & \multicolumn{2}{c}{ Temperatura $\left({ }^{\circ} \mathrm{C}\right)$} \\
\cline { 2 - 3 } (semanas) & Suínos & Aves \\
\hline 1 & 33 & 34 \\
2 & 30 & 32 \\
3 & 27 & 30 \\
4 & 24 & 28 \\
5 & 21 & 26 \\
6 & 18 & 24 \\
7 & 15 & 22 \\
\hline
\end{tabular}

\section{Comparador de temperatura}

Uma vez que as temperaturas são convertidas em tensões e essas terão de ser comparadas, utilizou-se de um amplificador operacional para tal tarefa. O amplificador operacional possui duas entradas, em que a diferença entre as duas tensões aplicadas às entradas é amplificada por um ganho muito alto, fazendo com que o amplificador operacional sature nas tensões positiva e negativa de alimentação. Esses níveis positivos e negativos de tensão são responsáveis por ligar e desligar o aquecimento das placas. O LM35D fornece tensões na ordem de milivolts, e o divisor de tensões utilizado opera na ordem de volts. Para que fosse possível comparar essas duas tensões, foi utilizado um amplificador operacional na configuração não-inversor, com ganho de 10 vezes.

\section{Atuador}

A saída do amplificador operacional fornece tensões na ordem de $5 \mathrm{~V}$ e $-5 \mathrm{~V}$ DC, muito inferiores aos 127 V AC que são aplicados à placa. Dessa forma, tornou-se necessária uma interface entre o circuito controlador de temperaturas e a resistência elétrica da placa, na qual é consumida grande potência. Essa interface foi feita por um opto-acoplador, o MOC3010, e um Triac, o Tic226.

\section{Composição do sistema de aquecimento}

Após a determinação de qual modelo de placa que melhor se enquadra para o sistema de aquecimento, foram construídas oito unidades desse modelo, as quais, conectadas em série e ao controlador eletrônico, formaram o sistema de aquecimento. O sistema foi então avaliado, regulandose o controlador para a temperatura de $32{ }^{\circ} \mathrm{C}$ (segunda semana de vida das aves), a fim de observar o desempenho térmico do sistema.

\section{RESULTADOS E DISCUSSÃO}

Durante a construção do sistema de aquecimento, foram realizados ensaios e testes, cujos resultados são apresentados a seguir. 


\section{Controle eletrônico da temperatura}

O componente LM35D mostrou-se bastante adequado ao projeto. Foi testado isoladamente e demonstrou medir corretamente a temperatura do ambiente no qual estivesse inserido. $\mathrm{O}$ circuito foi deixado funcionando ao ar livre e de acordo com a temperatura-base escolhida, foi constatado que ele ligava ou desligava conforme a temperatura ambiente se alterava.

Dessa forma, constatou-se que o controlador funcionou adequadamente durante os testes realizados. Em etapa posterior, observou-se o comportamento do controlador atuando nas placas.

\section{Resposta ao degrau}

Nesse teste, foi aplicada a uma única placa a tensão indicada pelo fabricante $(15,9 \mathrm{~V})$ por meio de um variac, que converte o nível de tensão da rede, $127 \mathrm{~V}$, na tensão desejada.

As temperaturas nas superfícies superior e inferior da placa foram medidas por um datalogger que obtinha esses dados através de nove termopares. Cinco deles foram colocados na superfície superior e quatro na superfície inferior da placa. Os dados obtidos nesse teste e o comportamento dos três modelos podem ser observados na Figura 4.

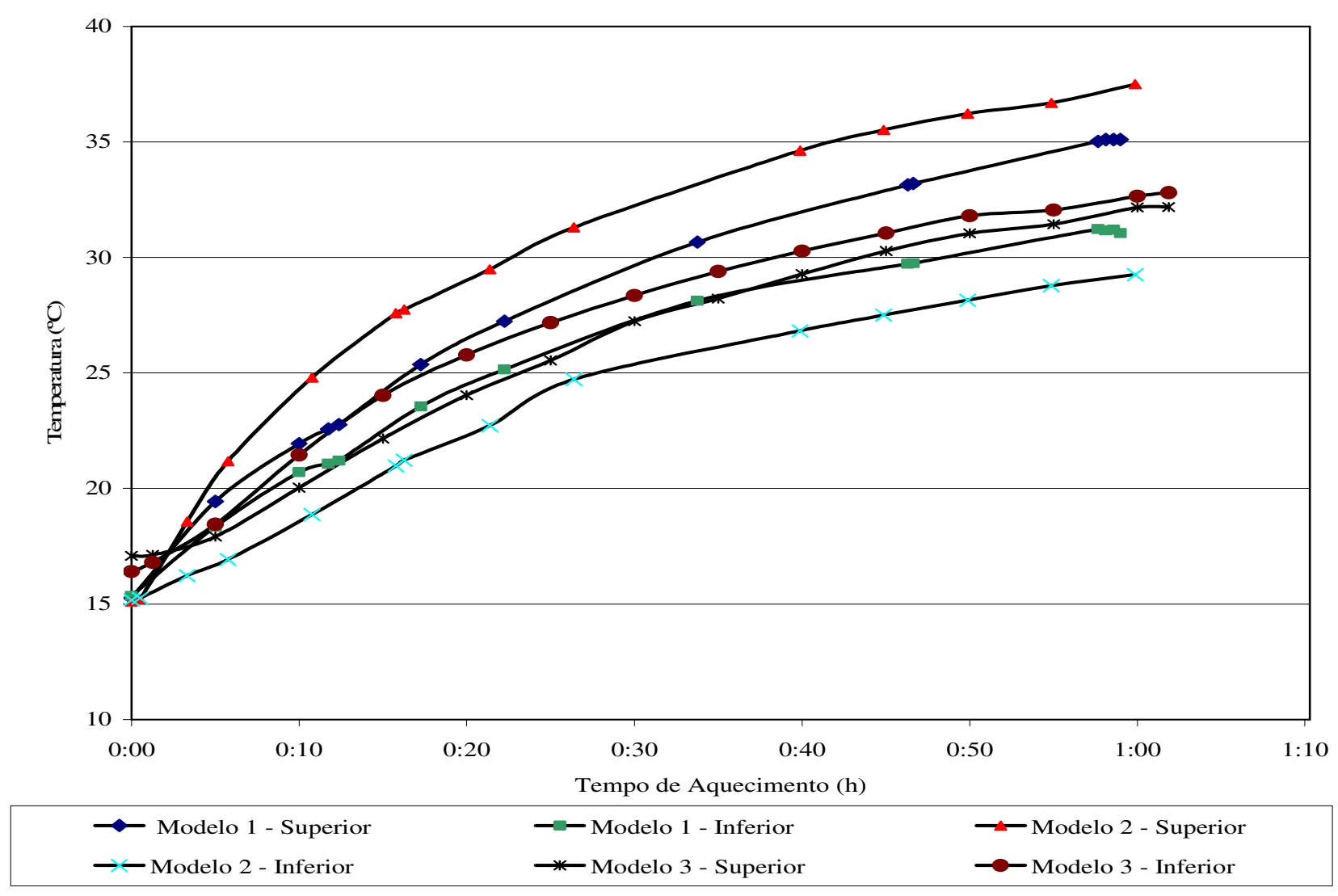

FIGURA 4. Resposta ao degrau de cada modelo de placa, média de temperatura.

A análise da Figura 4 indicou que a placa correspondente ao modelo 2 foi a que apresentou os melhores resultados. A diferença entre a temperatura superior e a inferior foi maior do que aquela correspondente às outras placas, além de ter atingido mais rapidamente, na superfície superior, a temperatura de $35^{\circ} \mathrm{C}$, a máxima que se pretendeu atingir com esse sistema de aquecimento. Deve ser notado que cada curva corresponde à média aritmética das medidas efetuadas pelos termopares, em cada uma das superfícies das placas. 


\section{Sistema de aquecimento}

Em função dos testes realizados, a formulação da placa correspondente ao modelo 2 foi escolhida para fazer parte do sistema de aquecimento. Assim, foram construídas mais cinco placas, totalizando, juntamente com as três construídas anteriormente, oito placas. Essas oito placas necessitam de $127 \mathrm{~V}$ nominais para aquecer, sendo essa a tensão fornecida na saída de potência do controlador.

As oito placas do modelo 2 foram conectadas em série e ao controlador, o qual foi regulado na temperatura de $32{ }^{\circ} \mathrm{C}$. O datalogger foi utilizado para efetuar a medição das temperaturas nas superfícies superior e inferior de uma das oito placas, tomada como piloto. Foram dispostos cinco termopares na parte superior, quatro na parte inferior, além de um outro cuja função era a de medir a temperatura ambiente. Na Figura 5, ilustra-se como foi realizado o ensaio do sistema de aquecimento.

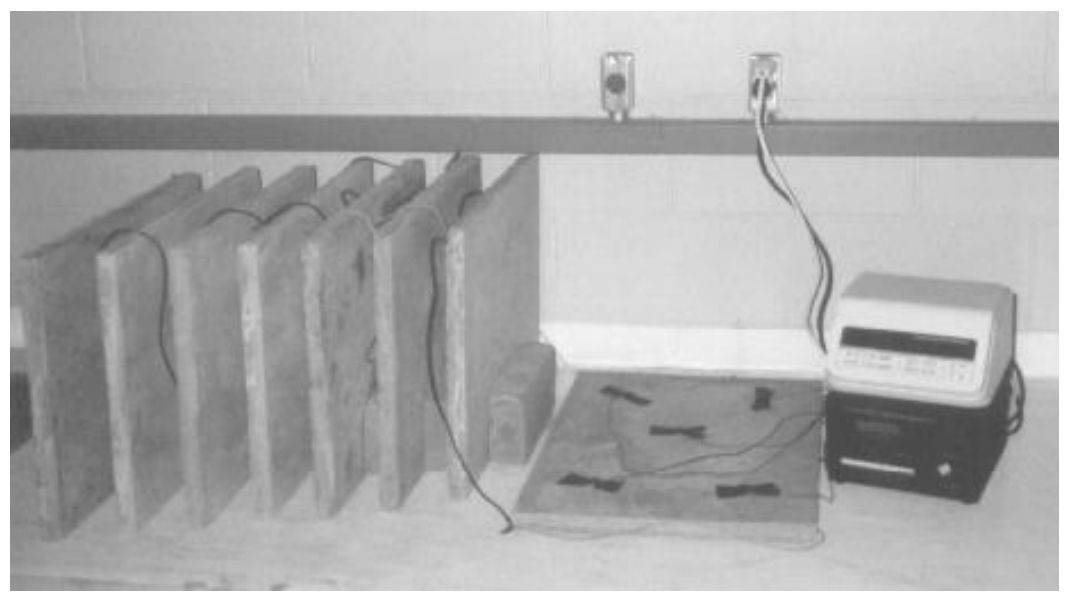

FIGURA 5. Ensaio do sistema de aquecimento.

A placa-piloto foi disposta na posição horizontal, pois essa é a posição final de uso (piso). As demais placas, juntamente com a placa-piloto, formam a carga elétrica total do sistema de aquecimento. Por esse motivo, não foi monitorada a temperatura por termopares ou sensores do controlador nessas placas, uma vez que isso não interferiria no resultado final do sistema, em função da uniformidade de confecção das placas.

$\mathrm{Na}$ Figura 6, indicam-se os resultados obtidos no ensaio do sistema de aquecimento. Pode-se constatar que o sistema de aquecimento funcionou como esperado, mantendo a temperatura na superfície superior bem próxima de $32{ }^{\circ} \mathrm{C}$, e que a temperatura da superfície inferior ficou abaixo daquela que havia sido regulada. Isso mostra que, apesar de a resistência elétrica estar na metade da placa, o fluxo de calor se direcionou mais para a superfície superior.

Também, observou-se que a temperatura ambiente não influenciou no funcionamento do sistema de aquecimento, para a faixa de temperatura do presente estudo. Nota-se que a curva de temperatura na superfície superior oscilou bastante. As variações foram pequenas, de décimos de grau, mas puderam ser notadas por meio do gráfico.

Isso indica que há histerese no sistema de aquecimento, devido à inércia térmica da placa. Esse fenômeno de histerese não deverá ser notado pelos animais, sendo tal fato benéfico ao controlador, pois não haverá a necessidade de chaveamentos rápidos no bloco de potência para manter a temperatura regulada. 


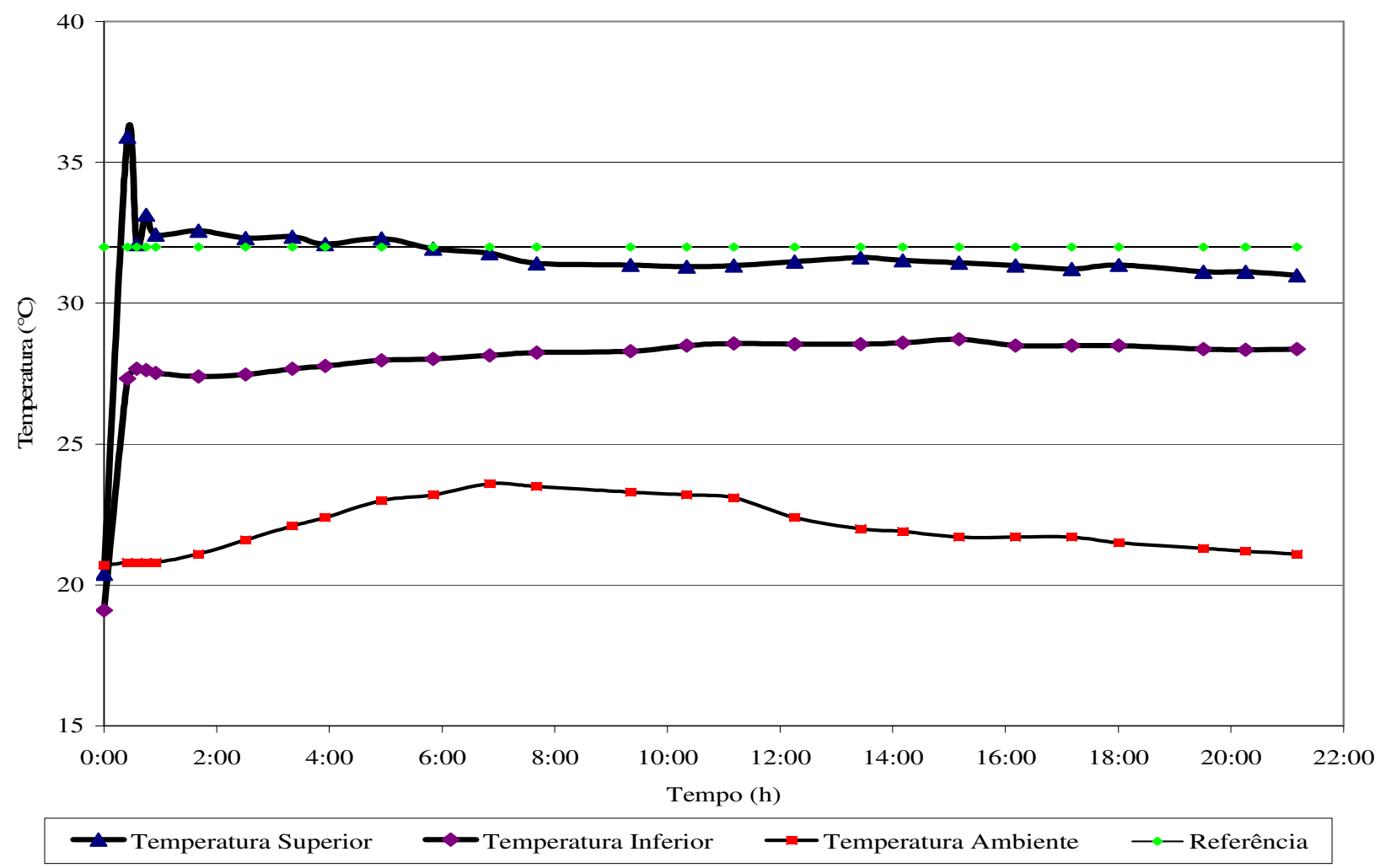

FIGURA 6. Resposta do sistema de aquecimento.

\section{CONCLUSÕES}

A argamassa de cimento, areia e casca de arroz mostrou-se um bom isolante térmico, sendo seu uso indicado para revestir a parte inferior das placas.

O protótipo do controlador eletrônico de temperaturas mostrou-se bastante versátil, uma vez que pôde ser ajustado em duas escalas diferentes de temperatura, ou seja, uma para aves e outra para suínos, além de possuir um ajuste fino que permite ao operador maior opção na escolha da temperatura desejada.

O sistema de aquecimento apresentou excelentes resultados, pois conseguiu manter a temperatura nas placas bem próxima da regulada, mostrando confiabilidade.

\section{AGRADECIMENTOS}

Ao CNPq, pela bolsa de pesquisa fornecida, e à FAPESP, pelo auxílio financeiro necessário.

\section{REFERÊNCIAS}

ABREU, P.G. Sistema de aquecimento em piso, com resistência elétrica, para criação de aves. 1994. 78 f. Dissertação (Mestrado em Engenharia Agrícola) - Universidade Federal de Viçosa, Viçosa - MG, 1994.

ÁVILA, V.S.; JAENISCH, R.F.; PIENIZ, L.C. Os pintinhos ao abrigo do frio. Aves \& Ovos, São Paulo, v.2, n.3, p.10-16, 1995. 
BERALDO A.L. Compósitos biomassa vegetal-cimento. In: GHAVAMI K.; TOLEDO FILHO, R.D.; NASCIMENTO W.J. Materiais não-convencionais para construções rurais. Campina Grande:

Universidade Federal da Paraíba/Marcone, 1997. p.1-48.

BERALDO A.L.; TOJAL J.H.V. Utilização de argamassa de cimento e casca de arroz em moradias populares. In: CONGRESSO BRASILEIRO DE ENGENHARIA AGRÍCOLA, 20., 2001, Foz do Iguaçu. Anais .... Cascavel: Sociedade Brasileira de Engenharia Agrícola, 2001. 1 CD ROM.

BACKSTROM, L.; CURTIS, S.E. Housing and environmental influences on production. In: LEMAN, A.A.; GLOC, R.D.; MENGELING, W.L.; PENNY, R.H.C.; SCHOOL, E.; STRAW, B. Disease of swine. $5^{\text {th }}$ ed. Ames: Iowa State University, 1981. p. 729-50.

CURTIS, S.E. Enviromental management in animal agriculture. Ames: Iowa State University, 1983. $409 \mathrm{p}$.

DEATON, J.W.; REECE, F.N. Special world's poultry issue implications of enviromental control for broilers. Feedstuffs, Minnetonka, v.1 n.42, p.34-6, 1970.

ESMAY, M.L. Principles of animal environment. Westport: Avi Publishing Company, 1982. 325 p.

MILLIGAN, J.L.; WINN, P.N. The influence of temperature and humidity on broiler performance in enviromental chambers. Poultry Science, Champaign, v.2, n.43, p. 817-24, 1964.

NÄÄS, I.A. Importância das instalações no controle do ambiente para produção de suínos.

Suinocultura, Piracicaba, v.3, n.2, p.1-10. 1990.

TOJAL J.H.V. Termorregulação de eqüinos em uma construção rural feita com blocos vazados de argamassa de cimento, areia e casca de arroz. 2002. 143 f. Dissertação (Mestrado em Construções Rurais e Ambiência) - Faculdade de Engenharia Agrícola, Universidade Estadual de Campinas, Campinas - SP, 2002.

. Princípios de conforto térmico na produção animal. São Paulo: Ícone, 1989. 129 p.

ZUCCO L.L. Estudo da viabilidade de fabricação de placas de compósitos à base de cimento e casca de arroz. 1999. 118 f. Dissertação (Mestrado em Construções Rurais e Ambiência) - Faculdade de Engenharia Agrícola, Universidade Estadual de Campinas, Campinas - SP, 1999. 